Article

\title{
Agricultural Business Strategy: Theory and Methods for Cost-Effectiveness Investment Analysis in Agro-Energy Production
}

\author{
Sonia Prestamburgo ${ }^{1, *}$ and Mario Prestamburgo ${ }^{2}$ \\ 1 Department of Engineering and Architecture, University of Trieste, V. Valerio 6/1, 34127 Trieste, Italy \\ 2 Department of Economic Sciences, Business, Mathematical and Statistical Sciences, University of Trieste, \\ V. Valerio 4/1, 34127 Trieste, Italy; m.prestamburgo@alice.it \\ * Correspondence: sprestamburgo@units.it; Tel.: +39-333-4270646
}

Academic Editor: Filippo Sgroi

Received: 9 March 2016; Accepted: 29 March 2016; Published: 6 April 2016

\begin{abstract}
Environmental change is currently considered a high-priority matter, both in the scientific community at large and at the institutional level of national and international governing bodies. Actually, an all-out effort seeks to investigate and advance viable solutions to deal with the global emergencies regarding to anthropic climate change; increasing demands for renewable sources of energy, technological innovation and energy-saving systems, ecological and environmental sustainability of natural resources and land. At the core of this worldwide endeavour an increasingly significant role seems destined to the agricultural sector and to agro-energy production systems for the potential benefits in terms of production costs. In fact, the interest in unconventional and low-impact energy sources mandates thorough investigation not only into the advantages, in terms of availability and affordability, but also into the impact on the environment and the quality of the landscape, as well as the aspects regarding the overall measures that need be adopted so as to enable the supply on the market. Given this scenario, the wide-ranging agro-energy question would be incomplete without extensive economic sustainability analyses, serving as operational decision-support tools to measure cost-effectiveness regarding investments in agro-energy production and its use.
\end{abstract}

Keywords: business strategy; agro-energy production; agricultural investment analysis; environmental sustainability

\section{Introduction}

Currently, environmental issues are one the most widely debated topics within the scientific community and governing bodies at the international and national levels. Faced with the prospect of rising energy demands, a common effort seeks viable solutions to a host of global emergencies resulting from anthropogenic climate change, in our quest for renewable sources, new technologies, energy conservation as well as the sustainable use of environmental resources and of the landscape.

The main underlying causes of the current global energy crisis can be narrowed down to several factors: an excessive demand for energy, particularly in countries undergoing accelerated industrial, economic and technological development, i.e., the BRICS; contraction and control of the supply on the part of supplier countries; rising prices of fossil fuels and their derivatives; general instability and uncertainty in the evolution of markets and economies worldwide.

With specific regard to Europe, despite the fact that the European Commission has urged that significant reductions be effected, in particular with to reference to the contents of the European Union (EU) Climate and Energy Package, Green Package 20-20-20, the increases in energy demands are 
forecasted to remain at exceedingly high levels until 2030 (cf. European Union Emissions Trading System, (EU ETS); Regulation (EU) No. 525/2013 of the European Parliament and of the Council of 21 May 2013 on a mechanism for monitoring and reporting greenhouse gas emissions and for reporting other information at national and Union level relevant to climate change and repealing, Decision No. 280/2004/EC; Decision No. 1386/2013/EU of the European Parliament and of the Council of 20 November 2013 on a General Union Environment Action Programme to 2020 “Living well, within the limits of our planet"; Energy Roadmap 2050, COM(2011)/885/final.) [1-9].

Given this scenario, an increasingly significant role has been assigned to the agricultural sector and to the production of agro-energy. Indeed, in view of the steady increase in production costs, new, unconventional and low-impact energy sources emerge as effective operational tools. Moreover, their availability and affordability enable us to pursue the objectives of protecting and enhancing the value of natural resources in rural areas, within an eco-systemic vision of built-in multi-functionality and sustainability of productive activities.

Be that as it may, the crucial factors to take into account are numerous as well as complex and comprise concerns in matters of: reliability, i.e., assuring an ample supply of the various energy sources over time; organizational aspects of their distribution throughout the territory; efficiency in terms of energy yields; repercussions of the alternative uses of natural spaces, i.e., assessment and management of the ensuing environmental impacts, accounting for every aspect of their multifaceted make-ups. Lastly, with reference to the need to systematize approaches to evaluation pertaining to the utilization of energy from existing renewable sources, no less crucial is the uncertainty that persists to date concerning the technological solutions currently available, an as yet unresolved matter and the focus of ongoing research and continuous innovation.

In the face of the challenges above, the bottom line is that a virtuous mutual coexistence between foodstuff and energy production, mindful of nature and the landscape as well as economic and social issues, appears anything but a foregone conclusion.

As for agro-energy production, the implementation of efficient and sustainable strategies entails the obligatory prerequisite of a substantial commitment on behalf of the various authorities in the territory, operating in synergy, with the aim of not only addressing environmental issues, but also of significantly improving the well-being of the local actors more or less directly involved.

The need to explore multi-level solutions and operational mechanisms that empower as many actors as possible is a compelling one, even in terms of having these very actors bear the onus of responsibility for choices and decision making. If, on the one hand, boosting knowledge and know-how in terms of planning tools, management skills and good governance practices concerning the territory and the rural landscape thus become crucial, no less strategic appear, on the other hand, promoting campaigns to raise the awareness of local communities and players through participatory approaches. From an exquisitely technological and procedural standpoint, the proliferation of agro-energy production must be bolstered by a widespread dissemination of key information and technical assistance, the streamlining of bureaucratic and administrative procedures, the upgrading of the supporting apparatus for projects with this specific aim, investments in advanced research in the field of energy efficiency and the experimentation of innovative technology and design solutions.

Any serious assessment regarding the possibilities of dissemination of agro-energy, therefore, must necessarily entail a thorough evaluation of every aforementioned aspect, comprehensive of an in-depth analysis in terms of economic viability, as a basis for taking cognizance of the profitability margins of such investments, whether subsidized or not, from the perspective of the producer of renewable energies as well as of the user, as an opportunity for agricultural enterprises to diversify their sources of income.

\section{Materials and Methods}

Considering the issues from the viewpoint of economic theory, or rather by applying its analysis tools, the assessment of the effects resulting from the dissemination of sources of agro-energy entails, 
as its corollary, the rigorous calculation of the profitability of the investments, as such. In the panorama of Italian agriculture the production of biomass for energy purposes originates in the context of firms specialized in monoculture farming and/or those whose production is diversified into a variety of goods and services, i.e., agro-industry producers capable of achieving real economies of scope. It follows that analyses of economic profitability of biomass production ought be carried out by applying standard concepts and measurement criteria of microeconomics. In this regard, the traditional method has been that of analytical crop cost accounting, which entails the determination of production costs, in the case of firms with mixed production systems. Yet, inasmuch as the latter method is characterized by a comparison between profits and production costs of different crops, based on estimates of "representative" companies in a given territory, it suffers from a high degree of heterogeneity, both economical and territorial, amongst production units, such that its application results rather complex. As a matter of fact the method has been so subject to criticism from its onset, as our readers know only too well, that we are refraining from further comment [10-15].

In contrast, a different economic analysis method called production-possibility frontier examines production tradeoffs for a farm producing alternative combinations of more than one commodity, based on the somewhat daring assumption of fixed total costs and resources. For the sake of simplicity, let us consider a farm producing only two types of goods: common wheat for human consumption $\left(\mathrm{Q}_{1}\right)$ and sunflower destined for energy production $\left(\mathrm{Q}_{2}\right)$. In addition, let us assume that the production levels of the company's two products are such that they bring no influence to bear on the goods' respective prices, $\left(\mathrm{P}_{1}\right)$ and $\left(\mathrm{P}_{2}\right)$, thus considered given, whilst allowing the firm to sell as much as desired. Under these conditions, the solution to the problem of the economic profitability of the investment for the entrepreneur seeking to the maximize profits with a given set of inputs (land and agricultural capital and labor) is shown in Figure 1.

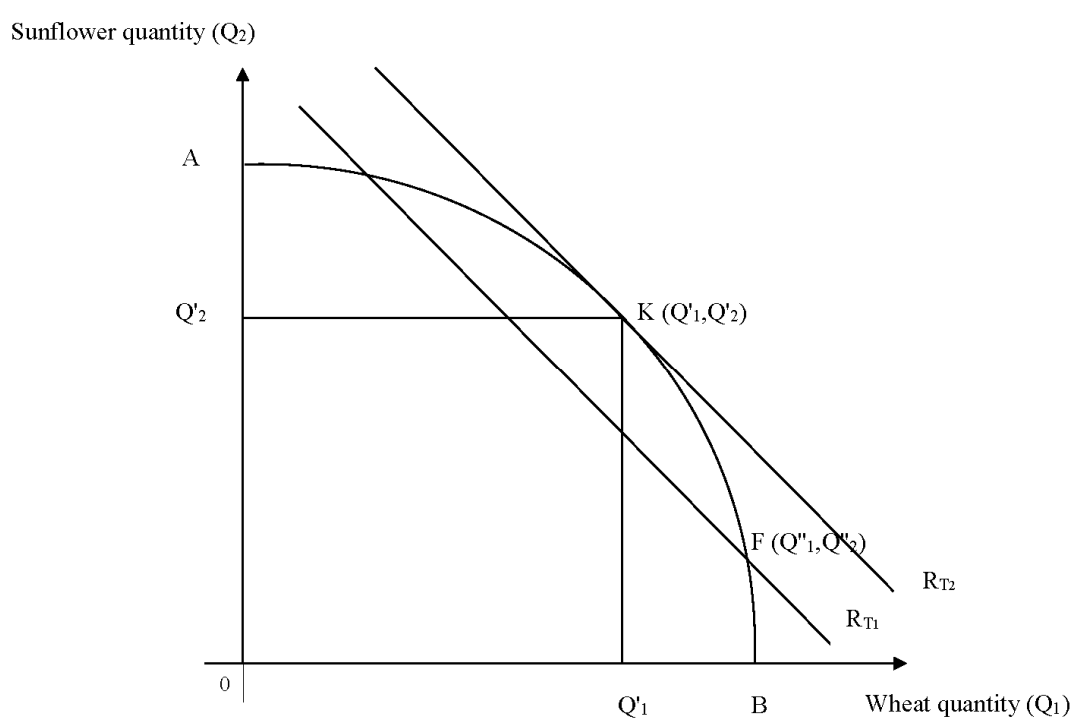

Figure 1. Economic profitability analysis according to production-possibility frontier.

The product transformation curve $(\mathrm{AB})$, or the production possibility frontier, represents every combination of possible outputs, in terms of wheat and sunflower production, using the available, fixed inputs. The underlying hypothesis appears decidedly theoretical, as it is well known that the production of alternative goods often entails very diverse technologies and therefore different global input levels, which, in turn, incur on the overall business costs to quite varying degrees. Furthermore, the method does not take account of economies or diseconomies of scale in production. The production possibility curve is necessarily descending, since an increase in the quantity of $\mathrm{Q}_{1}$ produced can only determine a decrease in the amount of $Q_{2}$. The absolute value of the slope at any given point on the curve is the marginal rate of transformation between the two products. In symbols, indicating with 
$\mathrm{K}=\mathrm{f}\left(\mathrm{Q}_{1}, \mathrm{Q}_{2}\right)$ the production function of wheat and sunflower, we have $\mathrm{f}\left(\mathrm{Q}_{1}, \mathrm{Q}_{2}\right)=\mathrm{K}$, whose total differential is given by the equation:

$$
\frac{\partial f}{\partial Q_{1}} d Q_{1}+\frac{\partial f}{\partial Q_{2}} d Q_{2}=d K
$$

Given that, in Equation (1), $\mathrm{dK}=0$, we get:

$$
\frac{d Q_{2}}{d Q_{1}}=-\frac{\partial f}{\partial Q_{1}} / \frac{\partial f}{\partial Q_{2}}
$$

which represents the marginal rate of transformation of both wheat and sunflower products. According to our assumption, the company's production costs are fixed, insofar as the quantities of factors of production remain constant over time, thus the entrepreneur will maximize profits when the total revenue, generated from selling the two commodities produced, is maximum. If $\mathrm{P}_{1}$ and $\mathrm{P}_{2}$ are the unit prices of wheat and sunflower, respectively, it follows that the total revenue $\mathrm{R}_{\mathrm{T}}$ is given by:

$$
R_{T}=P_{1} Q_{1}+P_{2} Q_{2}
$$

Assuming that prices $\mathrm{P}_{1}$ and $\mathrm{P}_{2}$ are given and thus not subject to modification by variations in the firm's production levels, we can identify the iso-revenue lines as follows:

$$
Q_{1}=\frac{R_{T}}{P_{1}}-\frac{P_{2}}{P_{1}} \cdot Q_{2}
$$

For each value of $\mathrm{R}_{\mathrm{T}}$ there is a corresponding iso-revenue line, but the slopes of each of these lines always remains constant and equal to $\mathrm{P}_{2} / \mathrm{P}_{1}$, i.e., the negative of the inverse price ratio.

With increasing values of $R_{T}$, the iso-revenue lines move rightwards, in parallel. By superimposing the iso-revenue lines onto the product transformation curve $(\mathrm{AB})$, graph 1 shows that the optimal conditions, which maximize profits for the enterprise, can be plotted by the tangent of the iso-revenue line of equation [16] to the product transformation curve $(A B)$. In fact, point $K\left(Q^{\prime}{ }_{1}, Q^{\prime}{ }_{2}\right)$ on the transformation curve belongs to the iso-revenue line $\left(\mathrm{R}_{\mathrm{T} 2}\right)$ furthest to the right. If the entrepreneur were to choose a different $Q_{1}$ and $Q_{2}$ combination, (for example point $F$ shown in Figure 1 ), this new production combination would belong to an iso-revenue line more to the left, thus entailing lower total revenues and profits. Only at point $\mathrm{K}$, in fact, is the relationship $\left(\mathrm{P}_{1} / \mathrm{P}_{2}\right)$ equal to the marginal rate of transformation of the two products considered:

$$
\left(\frac{\partial f}{\partial Q_{1}} / \frac{\partial f}{\partial Q_{2}}\right)
$$

It follows that the convenience for the entrepreneur to operate an investment in sunflower cultivation for purposes of energy production depends on the relationship between the prices of sunflower and other alternative products, which the company could produce by employing an allotted set of factors of production, thus with known and defined costs of production. On the basis of the above mentioned considerations, it is deemed that the cost-effectiveness analysis regarding the production of agro-energy requires the application of methods that take into full account all possible choices. Among these methods, the best known model is Linear Programming (LP), whose application has been the focus of studies regarding choices in agriculture $[17,18]$. In the case herein described, the objective (profit) function $\Pi$ is calculated by the following:

$$
\max \Pi=\sum_{i=1}^{n}\left(r_{i}-c_{i}\right) \cdot x_{i}-H
$$

where $\Pi$ represents the net return, $r_{i}$ the gross revenue per unit of production, $c_{i}$ the specific cost per unit of the $i$ th production process, $x_{i}$ the unknown for the dimension of the $i$ th production 
process, whereas $\mathrm{H}$ is a constant, which, in the short term, represents the enterprise's total fixed costs. The relation Equation (3) is subject to a set of constraints expressed as follows:

$$
\begin{cases}\sum_{j=1}^{m} & a_{j i} \cdot x_{i} \leqslant b_{j} \\ & x_{i} \geqslant 0\end{cases}
$$

in which $a_{i j}$ represents the technical processing coefficients of the $i$ th production process and $b_{j}$ is the $j$ th productive resource availability. Given that $x_{k}$ (with $1 \leqslant k \leqslant n$ ) represents the production process from which one obtains the biomass (e.g., sunflower) to be processed for energy, $a_{j k}$ its technical coefficients and $b_{j}$ the maximum surface area available for that crop, solving Equation (3), subject to the constraints of Equation (4) allows us to calculate the cost-effectiveness for the farm to cultivate crop $x_{k}$ (in the example, sunflower), in order to yield biomass for energy production.

\section{Results and Discussion}

The weight that the agricultural sector is bound to carry regarding the challenges we face in matters of climate and energy production is reflected in the programming strategies that have been promoted in the past decade at the international and EU levels, as well as at the national and regional levels, wherein the explicit reference is to the multifunctional role of the activities linked to the rural world.

The direction emerging from the Common Agricultural Policy (CAP) and its proposals for reform, together with the guidelines set out in the recent Rural Development Policy 2014-20, envision the sector within a framework capable of promoting development that is also compatible with the necessity to preserve and safeguard the landscape and natural resources. Moreover, the latter policies press for initiatives that seek to diversify income opportunities in agriculture, whilst integrating new dimensions so as to bolster forms of territorial governance. Thus, energy production represents a practical means for farms to broaden the scope of their activities, beyond the mere production of quality foodstuffs.

Increasing significance has been assigned to promoting synergistic initiatives aimed at addressing critical issues and environmental emergencies, by integrating agricultural, forestry and livestock farming measures, so as to bolster both rural economies and activities that safeguard and systematically enhance the value of the environmental heritage. Also, flexible agro-energy production chains are to be created, through efforts to systematize the various modalities of sustainable use of farmland, while biomass plants that produce and use such forms of energy are to be built, within a reorganized framework of territorial systems (cf. European Commission (2011), Energy Roadmap 2050, COM (2011) $885 / 2$, Communication from the Commission to the European Parliament, the Council, the European Economic and Social Committee and the Committee of the Regions, Bruxelles, Belgium.)

The proposed model allows one to evaluate the profitability of energy production from biomass whether for use on the farm, or destined to the market. Furthermore, the model allows one to account for existing EU and national agricultural policy subsidies in favor of producers of energy crops, incentives which may result in higher per unit revenues $\left(r_{k}\right)$ and/or lower per unit costs $\left(c_{k}\right)$ depending on the type of public intervention. Currently, the revised modalities of the disbursement of subsidies together with the still evolving regulatory framework concur in depicting an indistinct and ever-changing scenario.

Of note, we do acknowledge that the model illustrated herein is somewhat lacking in terms of representativeness of real-world farms, in view of the aforementioned considerations (linearity of the objective function and constraints, rigidity of the optimal solution...). Be that as it may, we nevertheless deem it an outstanding operational tool and far better than traditional ones.

Finally, it should be noted that, in the current scenario, for there to be any actual profitability in agro-energy production, Italian farming enterprises would have to first overcome two major obstacles: on the one hand their structural characteristics, both on an individual scale, given their modest dimensions, and in aggregate, consisting in the pulverization of operational units, which limit the 
dissemination and consolidation of energy crops within the territory; on the other hand, the sector lacks any effective coordination with respect to production much less does it provide for any feature of organization in terms of service provision to institutional users.

\section{Conclusions}

At present, the emergency linked to the effects of climate change and to the consequences of the progressive depletion of fossil fuels finds the political and economic decision-making efforts of industrialized and developing countries alike riddled with question marks. However, due to the increasingly complex and multifaceted nature of the environmental issues, whose intricate and interdependent aspects often defy comprehension, the actual magnitude of their impact may even go undetected. At the same time, the need to invest in the production and use of renewable energy sources has become a mainstay of the wide-ranging debate that involves public opinion the world over, such that it is universally perceived as a pressing matter that significantly contributes to an unsettling vision of our collective future, menacingly laden with uncertainties. Additional confusion and disorientation derive, on the one hand, from the abundance of media coverage and information overload (of sometimes questionable accuracy and/or depth), on the other hand, from the apparent incoordination of international institutions and national governments in identifying timely intervention programs and policies indicative of a shared strategy for the resolution of environmental emergencies globally $[19,20]$.

The plethora of regulatory and intervention analyses produced over the past several years all have in common an appeal to implement an urgent and radical, broad spectrum and cross-disciplinary scientific scheme: a project and an overarching planning effort to steer behavior, technological choices and the exploitation of natural and environmental resources on the planet [16].

It is against this backdrop that the issues concerning the further development of agro-energy sources need be addressed, albeit taking their specificity into due consideration. For such development to have any chance of success, operationally, there must be the perception on the part of the farmer of a tangible profitability regards energy crops per se, aside from incentives and subsidies, as a solid and economically viable investment entailing appreciable direct and indirect environmental benefits to be gained.

A crucial contribution in this regard can accrue from research, conducted at the scale of the individual farm, aimed at highlighting both the territorial specificities and the eventual benefits in those exemplary cases. In the primary sector, perhaps more so than elsewhere, the choice of productive investments needs to factor in the (often irreversible) modifications induced by alternative management options and uses of land and natural spaces. From the entrepreneur's perspective, these are high-stakes transformations, the repercussions of which actually transcend the local scale of the individual company. The increasing demand for farmland destined to the cultivation of energy crops in the primary sector also requires reliable assessments that take into account the interrelationships between the need to conserve the environment/landscape and the foreseeable trends in agricultural and energy markets, whilst ensuring an interdisciplinary approach to macro and microeconomic analyses.

The aim of the conversion of the agricultural sector to new lines of production thus appears hardly pursuable, or capable of taking root, nationally or internationally without a firm commitment and support on the political, economic and legislative fronts worldwide. Suffice it to recall the host of systemic issues which virtually undermine the effectiveness of the use of agro-energy: from the need for reorganization of the energy production and distribution sectors to the mapping out of forms of inter-professional coordination; from bringing to fruition the processes of liberalization and integration of markets to the standardization of regulatory frameworks; from promoting scientific research and honing the technology regarding the production, conversion and energy efficiency processes to the adoption of appropriate measures for the containment of investment and production costs.

In spite of the binding commitments for significant emissions reductions underwritten by Italy at the Community level, in our country there continues to be a marked distinction between the diffusion 
of "mature" renewable energy sources (hydro-electric, biomass, geothermal, wind) and those that still come under the heading of "immature technology" (photovoltaic and biofuels). The latter, from the standpoint of pursuing increasing levels of efficiency, must quickly be attuned to acceptable standards through a diversified investment plan at the territorial level that, nevertheless, comprises impact assessments regards the energy production from such renewable sources, in terms of modification of the landscape. The passage from proclamations of principle to the laying out of operational choices, disseminated nationwide, thus presents significant hurdles, which must be cleared with no further ado via political/economic efforts and regulatory frameworks that develop convincingly sustainable environmental policies, concerted and shared globally, that view the production of energy from renewable sources as the true mainstay for implementing proactive strategies and actions to safeguard environmental ecosystems on our planet [21]. With this sense of direction, we should acknowledge the crucial role played by the primary sector and the diverse realities of rural life, its operators and the agricultural economy as a whole, to identify effective mitigation systems in terms of choices of crops, uses of local resources (such as water, soil and landscape), sustainable economic investments, technological innovation, renewable energy production (agro-energy) and in particular biomass [22]. The latter orientation, in spite of its apparently consolidated features, nevertheless delineates an energy, economic and environmental horizon that is anything but certain: the inseparable connection amongst national and international energy strategies, quality of the environment and paths to economic development obliges us to commit to operational choices capable of accurately accounting for the impact and the after-effects of every negative externality generated by markets so as to find suitable remedies that, moreover, maintain their validity over the medium and long terms [23].

Author Contributions: This paper is the result of full collaboration between the authors. However, Sonia Prestamburgo wrote the Introduction and Materials and Methods sections while Mario Prestamburgo was responsible for elaborating the Results and Discussion and Conclusions sections.

Conflicts of Interest: The authors declare no conflict of interest.

\section{References}

1. Böhringer, C.; Löschel, A.; Moslener, U.; Rutherford, T.F. EU Climate Policy up to 2020: An Economic Impact Assessment. Energy Econ. 2009, 31, S295-S305. [CrossRef]

2. Strategie per il Clima: Dalle Regioni Alle Città. Linee Guida per lo Sviluppo di Politiche e Azioni di Riduzione dei Gas Serra nel Governo del Territorio; Cancila, E., Iraldo, F., Eds.; Franco Angeli Edizioni: Milano, Italy, 2011.

3. Commissione Europea. La Politica Agricola Comune dell'Unione Europea. Garantire un'evoluzione Parallela della Politica Agricola e di Sviluppo dell'Unione; Ufficio delle Pubblicazioni Ufficiali dell'Unione Europea: Luxembourg, Luxembourg, 2015.

4. Commissione Europea. Le Politiche dell'Unione Europea. Agricoltura. La Politica Agricola Comune dell'UE: Per la Nostra Alimentazione, le Nostre Campagne e il Nostro Ambiente; Ufficio delle Pubblicazioni Ufficiali dell'Unione Europea: Luxembourg, Luxembourg, 2014.

5. Planning for Climate Change: Strategies for Mitigation and Adaptation; Davoudi, S., Crawford, J., Mehmood, A., Eds.; Earthscan Ltd.: London, UK, 2013.

6. Despommier, D. The Vertical Farm. Feeding the World in the 21st Century; Thomas Dunne Books/St. Martin's Press: New York, NY, USA, 2010.

7. Klessmann, C.; Held, A.; Max Rathmann, M.; Ragwitz, M. Status and Perspectives of Renewable Energy Policy and Deployment in the European Union. What is needed to Reach the 2020 Targets? Energy Policy 2011, 39, 7637-7657. [CrossRef]

8. Intergovernmental Panel on Climate Change (IPCC). Climate Change 2014: Mitigation of Climate Change. Contribution of Working Group III to the Fifth Assessment Report of the Intergovernmental Panel on Climate Change; Edenhofer, O., Pichs-Madruga, R., Sokona, Y., Farahani, E., Kadner, S., Seyboth, K., Adler, A., Baum, I., Brunner, S., Eickemeier, P., et al., Eds.; Cambridge University Press: Cambridge, UK; New York, NY, USA, 2014. 
9. Intergovernmental Panel on Climate Change (IPCC). Meeting Report of the Intergovernmental Panel on Climate Change Expert Meeting on Climate Change, Food, and Agriculture; Mastrandrea, M.D., Mach, K.J., Barros, V.R., Bilir, T.E., Dokken, D.J., Edenhofer, O., Field, C.B., Hiraishi, T., Kadner, S., Krug, T., et al., Eds.; World Meteorological Organization: Geneva, Switzerland, 2015.

10. Fanno, M. Principi di Scienza Economica; CEDAM: Padova, Italy, 1963.

11. Giorgi, E. Alcuni Aspetti Delle Analisi Economiche Nell'azienda Agraria; Osservatorio di Economia Agraria per la Toscana: Firenze, Italy, 1962.

12. Medici, G. Principi di Estimo; Edizioni Agricole: Bologna, Italy, 1955.

13. Proni, G. Contributo Allo Studio del Costo di Produzione in Agricoltura; INEA: Roma, Italy, 1940.

14. Serpieri, A. Sui Metodi di Determinazione del Profitto Nelle Imprese Rurali: Analisi di Stima e Conti Colturali. L'Agricoltura Moderna; Tipografia Agraria: Milano, Italy, 1901.

15. Serpieri, A. Costi, Rendimenti, Imposte Nell'agricoltura; G. Barbera: Firenze, Italy, 1939.

16. Camboni, D. We Need to Make a Revolution, Interview with Economist Jeremy Rifkin, Dossier Clima, Energia e Futuro. Europei 2007, 6.

17. Ferro, O.; Lechi, F.; Prestamburgo, M. Scelte Economiche e Ricerca Operativa in Agricoltura; CEDAM: Padova, Italy, 1969.

18. Menzo, G. Le decisioni imprenditoriali al vaglio della programmazione lineare. Genio Rural. 1983, 10/11.

19. ENEA. Rapporto Energia e Ambiente 2013. Scenari e Strategie. Verso un'Italia Low Carbon: Sistema Energetico, Occupazione e Investimenti; Edizioni ENEA, Unità Comunicazione, Laboratorio Tecnografico ENEA: Frascati, Italy, 2014.

20. ENEA. Quaderno. Biomasse e Bioenergia; Edizioni ENEA, Unità Comunicazione, Laboratorio Tecnografico ENEA: Frascati, Italy, 2011.

21. Pareglio, S. Il Valore Dell'ambiente; Vita \& Pensiero: Milano, Italy, 2007.

22. Fiala, M.; Bacenetti, J. Model for the economic, energy and environmental evaluation in biomass productions. J. Agric. Eng. 2012, 43. [CrossRef]

23. Vieri, S. Biofuels and EU's choices. Int. J. Environ. Health 2012, 6, 155-169. [CrossRef]

(C) 2016 by the authors; licensee MDPI, Basel, Switzerland. This article is an open access article distributed under the terms and conditions of the Creative Commons by Attribution (CC-BY) license (http://creativecommons.org/licenses/by/4.0/). 